\title{
The COPDnet integrated care model
}

This article was published in the following Dove Press journal: International Journal of COPD

\author{
Eleonore H Koolen' \\ Philip J van der Wees ${ }^{2}$ \\ Gert PWestert ${ }^{2}$ \\ Richard Dekhuijzen' \\ Yvonne F Heijdra' \\ Alex J van 't Hul' \\ 'Department of Pulmonary Diseases, \\ Radboud University Medical \\ Center, Nijmegen, the Netherlands; \\ ${ }^{2}$ Radboud Institute for Health \\ Sciences, IQ Healthcare, Radboud \\ University Medical Center, Nijmegen, \\ the Netherlands
}

Correspondence: Eleonore H Koolen Department of Pulmonary Diseases, Raboud University Medical Center, PO Box 910I, 6500 HB Nijmegen, the Netherlands

Email noortje.koolen@radboudumc.nl
Introduction: This research project sets out to design an integrated disease management model for patients with COPD who were referred to a secondary care setting and who qualified for pharmacological and nonpharmacological intervention options.

Theory and methods: The integrated disease management model was designed according to the guidelines of the European Pathway Association and the content founded on the Chronic Care Model, principles of integrated disease management, and knowledge of quality management systems.

Results: An integrated disease management model was created, and comprises 1) a diagnostic trajectory in a secondary care setting, 2) a nonmedical intervention program in a primary care setting, and 3) a pulmonary rehabilitation service in a tertiary care setting. The model also includes a quality management system and regional agreements about exacerbation management and palliative care. Discussion: In the next phase of the project, the COPDnet model will be implemented in at least two different regions, in order to assess the added value of the entire model and its components, in terms of feasibility, health status benefits, and costs of care.

Conclusion: Based on scientific theories and models, a new integrated disease management model was developed for COPD patients, named COPDnet. Once the model is stable, it will be evaluated for its feasibility, health status benefits, and costs.

Keywords: COPD, COPD management, integrated care, Chronic Care Model, health status

\section{Introduction}

COPD is a highly prevalent disease and often puts a high burden of disease on those affected, even when they are in a relatively stable phase of their disease or only have mild-to-moderate airway obstruction. ${ }^{1}$ Moreover, the impact of COPD places an inordinate burden on health care resources given the significant direct and indirect costs of care. ${ }^{2}$ Projections on the future suggest a further rise in the prevalence of COPD patients, especially of patients with severe or very severe disease. ${ }^{3}$

Given this high prevalence, the expected rise, and the significant impact on the individual and on society, it is important to establish a care process that maximizes outcomes in relation to the efforts and costs made. ${ }^{4}$

Surprisingly, little scientific data are available on the outcome of "real-life" care in these patients in the chronic phase of their illness, that is to say, outcomes of care outside the remit of treatment of exacerbations. ${ }^{5}$ The first publications on the outcomes of real-life chronic care in COPD are available and suggest room for improvement for the organization of care, as well as for the content of care and the cost-effectiveness of care. ${ }^{6-9}$

Better outcomes of care for patients with chronic conditions, such as type 2 diabetes, are to be expected from the widespread use of integrated disease management programs. ${ }^{10}$ This also counts for patients with COPD. ${ }^{11}$ According to the definition of integrated disease management by Peytremann-Bridevaux and Burnand, ${ }^{12}$ such programs should address simultaneously both the content of care and the organization of 
care, that is to say, to provide 1) a patient-centered, holistic care based on the patient's individual needs, captured through a thorough assessment in 2) a synchronized manner with the coordination of services and therapies across health care settings and health care providers. ${ }^{13}$

The most recent systematic review confirmed the evidence for the efficacy of integrated disease management interventions in people with COPD of at least 3 months duration on disease-specific quality of life and exercise tolerance up to 12 months of follow-up and demonstrated a reduction in respiratory-related hospital admissions and hospital days per person. ${ }^{14}$ However, when taking a closer look at the studies, it appeared that only five of the 26 included studies described an integrated disease management program within a combination of primary and secondary health care settings. ${ }^{15-19}$ In addition, interventions were directed toward either the content of care ${ }^{15,16,19}$ or the organization of care ${ }^{17,18}$ but never addressed them together. A recent publication on the effects of the German disease management program for COPD, predominantly directed at primary care, also lends support to the effectiveness of an integrated approach for COPD. ${ }^{20}$

Finally, our impression is that integrated care models are, as yet, only in limited use in our present care delivery pathways. This was confirmed in a recently performed survey in five European Union countries, including the Netherlands. In this article, the authors concluded that COPD health care pathways are fragmented and care is not integrated properly. In order to succeed in providing integrated chronic disease management care, knowledge from controlled studies should be translated into practical applications. ${ }^{21}$

This article describes the results of a research project, which was set out to design an integrated disease management model for patients with COPD, named the COPDnet integrated care model. This model may serve as a blueprint for the establishment of regular care for COPD patients across all health care settings, and it will address both the content and the organizational aspects of care. The COPDnet integrated care model was specifically designed for patients with moderate or severe burden of disease, who, according to the Dutch Standard of Care for COPD, meet the criteria for care in a primary, secondary, or tertiary care setting and qualify for both pharmacological and nonpharmacological intervention options. ${ }^{22}$

\section{Description of the care practice Description of the development process}

The COPDnet integrated care model was designed according to the guidelines of the European Pathway Association (EPA) in which the following seven phases are distinguished: 1) a screening phase, 2) a project management phase, 3) a diagnostic phase (baseline measurements, mapping existing pathways), 4) a design and plan phase (development of care pathway), 5) an implementation phase, 6) an evaluation phase, and 7) a continuous follow-up phase (making it clinical routine and ongoing review). ${ }^{23}$ We designed this model because it seemed particularly applicable to in-hospital, primary care, and cross-boundary projects. In Phase II and III, an analysis and baseline measurements were carried out and we found that the process of care at that time did not sufficiently comply with the principles of integrated disease management care. During the course of Phase IV, the designing process, general practitioners (GPs), respiratory nurses, pulmonologists, representatives of the Dutch Lung Foundation, and medical advisors of health insurance companies externally reviewed the COPDnet integrated care model.

\section{The content of the COPDnet model}

The definition of chronic disease management was used as a starting point for the development of the COPDnet integrated care model. ${ }^{12}$ In order to operationalize this definition in the designing process, we have used the Chronic Care Model (CCM) as a guideline. ${ }^{24}$ The CCM sets out to transform the daily care for patients with chronic illnesses from acute and reactive to proactive, planned, and population based. ${ }^{25}$ Moreover, application of the principles of the CCM in the context of COPD has shown added value and highlighted the need for implementing multiple components of the CCM to prevent complications and improve outcomes in patients with COPD. ${ }^{26}$ Therefore, the following four elements of the health care system, as identified in the CCM, were used in our COPDnet integrated care model: 1) self-management support, 2) decision support, 3) delivery system design, and 4) clinical information systems. The CCM is not an explanatory theory, yet the model is more like a flexible evidence-based guideline. ${ }^{27}$ We have added specific diagnostic procedures to our model in order to better address the complexity and heterogeneity of COPD and thereby to provide the best personalized treatment of a given patient. ${ }^{28}$

Figure 1 represents a graphical overview of all the elements of the COPDnet integrated care model, that is, 1) a diagnostic trajectory carried out in a secondary care setting, 2) a nonmedical intervention program in a primary care setting, and 3) a pulmonary rehabilitation service in a tertiary care setting. The model also includes a Quality Management System (QMS) and a set of regional network agreements about exacerbation management and palliative care. The COPDnet model uses the diagnostic trajectory of which one of the authors (AJvtH) was cocreator and is based on the Delphi Panel Study. ${ }^{29}$ Novelties in this diagnostic 


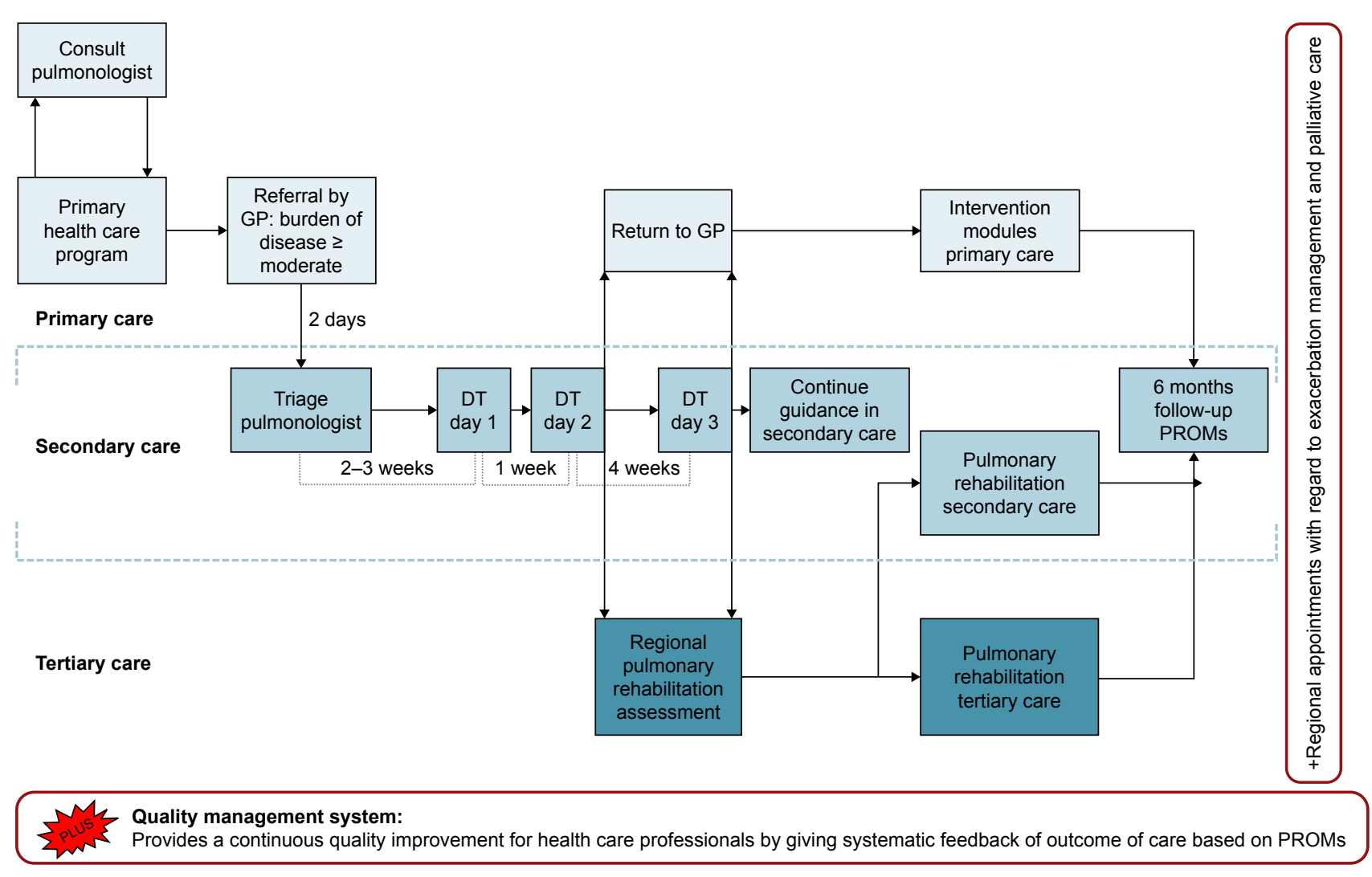

Figure I The COPDnet integrated care model.

Abbreviations: DT, diagnostic trajectory; GP, general practitioner; PROMs, Patient-Reported Outcome Measurements.

trajectory are a measurement of dynamic hyperinflation, an objectivation of physical activity measured with the DynaPort MoveMonitor (McRoberts, The Hague, the Netherlands), and a systematic evaluation of the burden of disease measured with the Nijmegen Clinical Screening Instrument (NCSI). The identification of comorbidities is explicitly part of the diagnostic workup in the COPDnet model and is acted upon if and when this is deemed appropriate by the pulmonologist. ${ }^{30}$ Details regarding the content of the diagnostic trajectory are published elsewhere. ${ }^{31}$

We describe how the four CCM components have been integrated in the COPDnet model in detail below.

\section{Self-management support}

More and more, the reinforcement of self-management skills is found to be an important aspect in the care of patients with a chronic health condition. An effective self-management strategy should include the initiation of behavioral change, be tailored individually, take the patient's perspective into account, and be adapted to the course of the patient's disease and comorbidities. ${ }^{32}$ Recently, international consensus has been reached regarding a conceptual definition of what a COPD self-management intervention should comprise. ${ }^{33}$
Subsequently, we have included the following strategies for self-management support in our COPDnet model: 1) Patient Activation Measurement (PAM) and Motivational Interviewing, 2) Capabilities Opportunities MotivationBehavior (COM-B) model, 3) shared decision making, and 4) an individual care plan.

\section{PAM and Motivational Interviewing}

An understanding of the level of activation for selfmanagement, defined as "patients' knowledge, skills, and self-efficacy regarding self-management" is important because it gives clues as to how self-management may be improved by the individual patient. ${ }^{34}$ The level of activation for self-management can be determined with the PAM..$^{34,35}$ In the COPDnet integrated care model, we use the shortened 13 -item version of the PAM. ${ }^{34}$ This measures patients' activation levels for self-management and classifies patients into the following four different levels: 1) believing in the importance of their own role, 2) having the confidence and knowledge required to take action, 3) actually taking action to maintain and improve health, and 4) staying the course even under stress. With the outcome of the PAM, the stages of change in health behavior can be monitored. ${ }^{36}$ Based on these outcomes, 
health care professionals apply motivational interviewing techniques to improve patients' self-management skills. Motivational interviewing is a communication technique, which focuses on helping patients to change their behaviors, by exploring their personal perspectives as well as their perceived barriers. ${ }^{37}$

\section{COM-B model}

The COM-B model is a theoretical model, which suggests that there are three ways in which human behavior (B) results from the interaction between: psychological capabilities (C), social and environmental opportunities $(\mathrm{O})$, and motivation (M). This model helps to identify which dimension in this COM-B model should be addressed to encourage behavioral change in patients. ${ }^{38}$

\section{Shared decision making}

Shared decision making is used in our COPDnet model. Although the principles of shared decision making are well documented, we have described a comprehensive practical approach to patient-centered care. Achieving shared decision making relies on a good relationship in the clinical encounter so that information is shared and patients are supported to deliberate and express their preferences and views during the decision-making process. ${ }^{39}$ Shared decision making is based on introducing a choice (choice talk), describing options (option talk), and helping patients to explore preferences and to make informed decisions (decision talk). ${ }^{39}$ In our COPDnet model, the choice talk takes place during day 1 , the option talk takes place during day 2 , and the decision talk takes place during day 3 of the diagnostic trajectory.

\section{Individual care plan}

Based on the various talks between the health care professionals and the patient, the patient is asked to construct an individual care plan - including the patient's personal objective(s) - between visits 2 and 3. During visit 3, this individual care plan will be further explored with the respiratory nurse and developed into informed preferences regarding treatment options.

\section{Decision support}

\section{Guidelines on decision making}

Based on state-of-the-art insights, practical guidelines on decision making were introduced in our model for 1) additional diagnostics, 2) classification of the burden of disease, and 3 ) choices between care settings for personalized interventions.

\section{Additional diagnostic tests}

The COPDnet diagnostic trajectory is designed to provide an optimal diagnosis with minimal measurements, as adequately as possible. The model creates an overview of the individual traits of each patient. In some patients, a further understanding of the pathophysiology is necessary in order to come to a proper diagnosis or to set an appropriate indication for the best interventions. For these patients, additional diagnostics may be required after day 1 of the diagnostic trajectory. In patients to whom exercise training is offered as intervention, a cardiopulmonary exercise test is carried out. The performance on a maximal exercise test is used to set individual training parameters. ${ }^{40}$ Further diagnostic tests may be requested (Table 1).

Table I Additional diagnostics

\begin{tabular}{|c|c|c|}
\hline Additional diagnostics & Aim & Indication \\
\hline $\begin{array}{l}\text { Measurement of static lung } \\
\text { volumes }\end{array}$ & $\begin{array}{l}\text { To determine the presence of restrictive } \\
\text { pulmonary function impairment }\end{array}$ & - FVC $<80 \%$ of the predicted value \\
\hline CO diffusion capacity & $\begin{array}{l}\text { To determine whether or not } \mathrm{CO} \\
\text { diffusion is limited }\end{array}$ & $\begin{array}{l}\text { - Persisting doubts about the diagnosis of asthma or COPD } \\
\text { - Suspected ILD } \\
\text { - Discrepancy between spirometric values and desaturation } \\
\text { during the 6MWD }\end{array}$ \\
\hline Histamine provocation test & $\begin{array}{l}\text { To determine the presence and severity } \\
\text { of bronchial hyperreactivity }\end{array}$ & $\begin{array}{l}\text { - Doubts about the diagnosis of asthma or COPD } \\
\text { - To set up or adjust medication in case of asthma }\end{array}$ \\
\hline Cardiopulmonary exercise test & $\begin{array}{l}\text { To determine maximal exercise capacity } \\
\text { and cause of exercise limitation }\end{array}$ & $\begin{array}{l}\text { - Steps per day }<5,000 \text { or VMU }<0.210 \text { and } 6 \mathrm{MWD}<70 \% \\
\text { of predicted value and the patient is willing to participate } \\
\text { in an exercise training program }\end{array}$ \\
\hline CT thorax & Imaging of the thorax & - Doubts about the presence of malignancy or ILD \\
\hline $\begin{array}{l}\text { Referral to cardiologist or ENT } \\
\text { specialist }\end{array}$ & $\begin{array}{l}\text { To determine the diagnosis and } \\
\text { treatment of relevant comorbidity }\end{array}$ & - Suspicion of relevant cardiac or ENT comorbidity \\
\hline
\end{tabular}

Abbreviations: 6MWD, 6-minute walk distance; CO, carbon monoxide; CT, computed tomography; ENT, ear nose throat; FVC, forced vital capacity; ILD, interstitial lung disease; VMU, vector magnitude units. 


\section{Classification of burden of disease}

The diagnostic trajectory of the COPDnet model aims to provide a classification of the burden of disease on the patient. Subsequently, this classification is used for the allocation of patients to the appropriate care setting, which means either a referral back to a primary care setting or a referral to a tertiary care setting for a pulmonary rehabilitation assessment.

Whereas the severity of COPD is defined by the pathophysiological impairment (airway obstruction), the burden of disease is based on the perceived health problems by the individual patient. ${ }^{41}$ This allows tailoring treatment to the patient, based on a comprehensive assessment of the individual causes of the burden of disease. The severity of the burden of disease is classified into mild, moderate, and severe (Table 2). Choices with respect to the indices of and cutoff values for the burden of disease in our model are partially based on the existing literature and the expert opinion based on such thresholds, for instance, to classify the 6-minute walk distance.

\section{Choices between care settings for personalized interventions}

During the diagnostic trajectory in a secondary care setting, 1) the medical diagnosis is confirmed, 2) classification of the burden of disease is made, and 3 ) the number and complexity of individual traits are determined. The classification of the burden of disease leads to the next phase, that is, referral to a primary, secondary, or tertiary care setting for tailor-made interventions. An important aim of the COPDnet model is the provision of appropriate care of patients as close as possible to their home environment, that is, preferably in a primary care setting and, only if necessary, in a secondary or tertiary care setting.

In principle, patients with mild or moderate burden of disease are (re)referred to a primary care setting and, according to their individual care plan, will be offered one or more nonmedical intervention module(s) provided by allied health care professionals. In order to enable referral of the right patients to the appropriate nonmedical intervention module(s), a guideline on decision making was developed for the allocation of COPD patients to modules provided by dieticians, occupational therapists, and physiotherapists (Figure 2).

Patients with a severe burden of disease may be referred to a pulmonary rehabilitation setting, where an additional prerehabilitation assessment is carried out and the indication for pulmonary rehabilitation is re-established. Again, personal goals are set and the components of the rehabilitation program are determined, which means that either an inpatient-based rehabilitation program or an outpatient-based rehabilitation program is indicated..$^{42}$

In the case of such an indication, patients continue under supervision for some time in a secondary care setting by the pulmonologist and/or respiratory nurse. Typically, this applies to patients who were not on the appropriate inhalation medication yet, as recommended by current guidelines. Also, when more time is required to reach an agreement with the patient on the individual care plan.

\section{Multilevel outcome measurement}

Most importantly, we deliberately set out to include a systematic registration of the outcome of care at multiple

Table 2 Classification of burden of disease

\begin{tabular}{|c|c|c|}
\hline Mild & Moderate & Severe \\
\hline - Exacerbations: none in the last year & - Exacerbations: one in the last year & $\begin{array}{l}\text { - Exacerbations: } \geq 2 \text { in the last year or one } \\
\text { hospitalization due to exacerbation COPD }\end{array}$ \\
\hline $\begin{array}{l}\text { - Comorbidities: none or do not contribute } \\
\text { to the burden of disease }\end{array}$ & $\begin{array}{l}\text { - Comorbidities: present and contribute } \\
\text { moderately to the burden of disease }\end{array}$ & $\begin{array}{l}\text { - Comorbidities: present and contribute } \\
\text { markedly to the burden of disease }\end{array}$ \\
\hline$-M R C=0-1$ & $-M R C=I-2$ & $-M R C=3-5$ \\
\hline$-\mathrm{BMI}>2 \mathrm{I}$ or $<30$ & $-\mathrm{BMI}<2 \mathrm{I}$ or $30-35$ & $-\mathrm{BMI}<2 \mathrm{I}$ or $>35$ \\
\hline$-6 M W D \geq 500 \mathrm{~m}$ & $-6 M W D=400-500 \mathrm{~m}$ & $-6 M W D<400 m$ \\
\hline$-P A L \geq 1.7$ & $-P A L=I .4-I .7$ & $-\mathrm{PAL}<\mathrm{I} .4$ \\
\hline$-\mathrm{CCQ}<2.0$ & $-C C Q=2-3$ & $-\mathrm{CCQ}>3.0$ \\
\hline - NCSI = normal or mildly disturbed & $-\mathrm{NCSI}=$ moderately disturbed & $-\mathrm{NCSI}=$ severely disturbed \\
\hline $\begin{array}{l}\text { - No or mild disturbance of the social } \\
\text { participation (work, family, hobbies, } \\
\text { sports, and so on) }\end{array}$ & $\begin{array}{l}\text { - Moderate disturbance of the social } \\
\text { participation (work, family, hobbies, } \\
\text { sports, and so on) }\end{array}$ & $\begin{array}{l}\text { - Severe disturbance of the social } \\
\text { participation (work, family, hobbies, } \\
\text { sports, and so on) }\end{array}$ \\
\hline
\end{tabular}

Note: PAL was measured with the MoveMonitor.

Abbreviations: 6MWD, 6-minute walk distance; BMI, body mass index; CCQ, Clinical COPD Questionnaire; MRC, Medical Research Council; NCSI, Nijmegen Clinical Screening Instrument; PAL, physical activity level. 


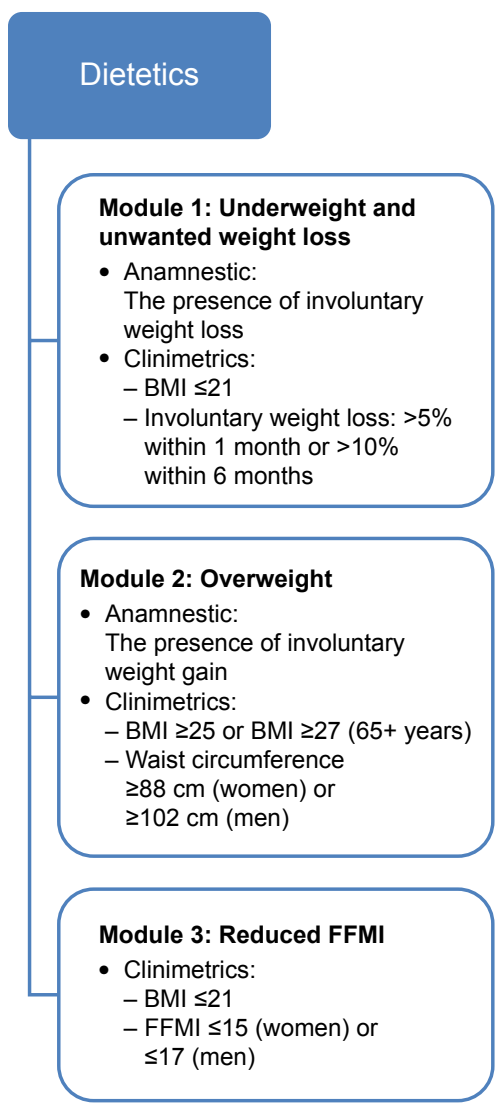

Physical

therapy

Module 1: Control your coughing

- Anamnestic:

The presence of a chronic productive cough associated with symptoms (dyspnea), restrictions, and/or participation problems

- Clinimetrics:

- CAT score >10

- CCQ subdomain symptoms score $>1.5$

Module 2: Control your breath -

dyspnea

- Anamnestic:

The presence of dyspnea interfering with the performance of daily activities, so that these daily activities cannot (or cannot as desired) be performed

- Clinimetrics:

- The NCSI scores yellow or red on $\geq 1$ of the subdomains (severity, impact, activity) of the domain dyspnea

- CAT score >10

- CCQ subdomain symptoms score $>1.5$

- MPT test, after bronchodilation, an $\mathrm{IC}$ reduction of $>10 \%$

Module 3: Control your breath hyperventilation

- Anamnestic:

The presence of chronic hyperventilation and thereby related complaints

- Clinimetrics:

- Blood gas: $\mathrm{pCO}_{2}<4.7 \mathrm{kPa}$ plus $\mathrm{BIC}<23.0 \mathrm{mmol} / \mathrm{L}$

- Nijmegen hyperventilation questionnaire score $>23$

Module 4: Train your body

- Anamnestic:

Limited physical activity in daily life in combination with a limited exercise capacity

- Clinimetrics:

$-6 \mathrm{MWD}<70 \%$ of the predicted value in combination with the number of steps per day $<5,000$ or $\mathrm{PAL}<1.4$

Figure 2 Guideline on decision making for nonmedical intervention modules in a primary care setting. Note: PAL was measured with the MoveMonitor.

Abbreviations: 6MWD, 6-minute walk distance; BIC, blood isotope clearance; BMI, body mass index; CAT, COPD assessment test; CCQ, Clinical COPD Questionnaire; FFMI, Fat-Free Mass Index; IC, inspiratory capacity; MPT, manually paced tachypnea; NCSI, Nijmegen Clinical Screening Instrument; PAL, physical activity level; pCO, partial pressure of carbon dioxide.

levels in the COPDnet model, using Patient-Reported Outcome Measurements (PROMs): 1) NCSI, 2) Clinical COPD Questionnaire (CCQ), and 3) 13-PAM. Data from the NCSI and CCQ are collected on day 1 of the diagnostic trajectory
Occupational

therapy

Module 1: Control your breathing

- Anamnestic:

The presence of dyspnea interfering with the performance of daily activities, so that these daily activities cannot (or cannot as desired) be performed

- Clinimetrics:

- The NCSI scores yellow or red on one or more of the subdomains (severity, impact, activity) of the domain "Dyspnea", or, one or more of the subdomains (home, walking, perception) of the domain "Restrictions", or, the subdomain (physical functioning) of the domain "Satisfaction"

- CAT score >10

- CCQ subdomain symptoms score $>1.5$

Module 2: Control your fatigue

- Anamnestic:

The presence of chronic fatigue interfering with the performance of daily activities, so that these daily activities cannot (or cannot as desired) be performed

- Clinimetrics:

- The NCSI scores yellow or red on the domain "Fatigue"

- CCQ subdomain "Functional restrictions" score $>1.5$

Module 3: Healthy active

- Anamnestic: Limited physical activity in daily life with a relatively preserved exercise capacity

- Clinimetrics:

$-6 \mathrm{MWD} \geq 70 \%$ of the predicted value in combination with the steps per day $<5,000$ or $\mathrm{PAL}<1.4$ and on 6 months follow-up. The outcomes of the 13-PAM are also collected on day 1 of the diagnostic trajectory, the last day of the diagnostic trajectory (day 2 or 3), and also 6 months follow-up. 


\section{$\mathrm{NCSI}$}

The NCSI enables the clinician to obtain a valid, reliable, and detailed picture of a patient's health status by measuring multiple sub-domains covering the following four domains: physiological functioning, symptoms, functional impairment, and quality of life. ${ }^{43}$ In combination with the automated monitoring system of the Patient Profile Chart, the NCSI can easily be used in routine care as a guide to patient-tailored treatment. ${ }^{43}$ The Patient Profile Chart offers a visual and, therefore, easily interpretable picture of the integral health status of an individual patient for the pulmonologist, respiratory nurse, and the patient. ${ }^{44}$

\section{CCQ}

The CCQ is a self-administered 10-item questionnaire specially developed to measure clinical control in patients with COPD. Data support the validity, reliability, and responsiveness of this questionnaire. ${ }^{45}$

\section{I3-PAM}

The 13-PAM is a valid and reliable 13-item Guttman-like scale and assesses the level of activation for self-management. ${ }^{34,35}$

\section{Delivery system design}

\section{Cohesive, transmural model}

The COPDnet model also aims to improve the transmural, organizational aspects of care. In order to do this, we operationalized the following in our model: 1) standardization of (electronic) referral procedures for the GP to a secondary care setting, 2) proactive management of the patient's expectations by the GP, 3) preparation of patients for the setting of goals after the diagnostic trajectory (information provided by an information flyer), 4) standardization of reporting by the pulmonologist and respiratory nurse, and 5) agreements as to what information is provided to allied health care providers when referring a patient for an intervention module.

Finally, every 3 months, consultation takes place between representatives of health care providers from primary and secondary care settings and between representatives of secondary care and the regional tertiary care rehabilitation center to discuss organizational aspects of care.

\section{QMS}

Based on the knowledge of quality management models, and in collaboration with the participating health care professionals, we developed a QMS primarily focused on the diagnostic trajectory in secondary care settings. The QMS aims to provide a continuous quality improvement for pulmonary specialists and respiratory nurse specialists participating in the COPDnet integrated care model, by giving systematic feedback on outcomes of care based on PROMs. The COPDnet QMS includes 1) case presentation and discussion, 2) audit, and 3) education and training.

\section{Case presentation and discussion}

Every 3 months, one to two case histories are presented by the pulmonologist and respiratory nurse and then discussed with a psychologist and an independent chairman. ${ }^{46}$ Discussions may cover the interpretation of health status measurements, interviewing techniques, decisions on additional diagnostic tests and classification of the burden of disease, or choices with regard to the individual care plan. Mirroring the COPDnet guidelines, decision making is an important element in this process.

\section{Audit}

Audits are regularly performed between health care professionals from different hospitals working with the COPDnet model to evaluate and to discuss the aspects of the organization of the care process. ${ }^{47}$ Sharing experiences between users are thought to be helpful to further optimize the model.

\section{Education and training}

Education and training sessions are offered depending on the specific needs indicated by the health care professionals. The topics of the education and training may vary, but they are always related to the COPDnet model.

\section{Exacerbation management and palliative care}

In the COPDnet model, regional action plans with regard to exacerbation management and palliative care were agreed. ${ }^{48,49}$

\section{Clinical information systems}

\section{Electronic Health Record (EHR)}

An EHR is used to register key administrative and clinical data of patients during the diagnostic trajectory of the COPDnet model. Relevant clinical parameters for the evaluation of the individual health status at baseline, as well as the change of health status over time, systematically registered in the EHR. The data may be used to support the clinical decisionmaking process at the individual level and may also be used in aggregated (anonymized) data at the population level for quality purposes, as well as for scientific research purposes. Also, important features with regard to the care process are periodically analyzed. 


\section{Electronic communication platform}

To facilitate digital communication between health care professionals and the patient in the COPDnet model, a patient portal is used, for instance, to exchange information or to enable the administration of questionnaires at home at regular intervals. This portal is considered an important digital add-on contributing to the effectiveness of the care model but also to the perceived quality of care by patients.

\section{Discussion}

With the current project, we wish to present an evidencebased comprehensive integrated disease management model for patients with COPD with moderate or severe burden of disease, who, according to the Dutch Standards of Care for COPD, meet the criteria for shared care between primary and secondary care settings. ${ }^{22}$

The idea behind this project arose from the awareness of the poor and fragmented use of the principles of integrated care in COPD patients in real-life care in various health care settings. ${ }^{21}$ This is not in keeping with the scientific evidence of the added value of an integrated approach, in terms of improving the quality and the efficiency of care and reducing health care costs..$^{50}$ In addition, the first observational studies on the outcome of real-life COPD care, recently carried out in Germany, demonstrated extensive room for improvement. ${ }^{6-9}$ More studies on the outcome of real-life COPD care are expected in due time. ${ }^{51-53}$ Last but not least, the poor outcome observations are in line with a recently performed survey in five European Union countries, including the Netherlands, in which the authors concluded that COPD health care pathways are fragmented and care is not integrated properly. ${ }^{21}$

We assume that the availability of a scientifically documented care pathway, based on principles of integrated disease management and founded on the CCM, may facilitate the wider use of the principles of integrated disease management care in real-life clinical practice and that it will boost the clinical effectiveness of care in COPD patients. Evidence in support or this assumption is the outcome of a study on the effects of the introduction of a QMS-targeting patients treated on an outpatient base in hospitals in Denmark. In this study, it was found that with the implementation of a nationwide registration, the care provided was more in line with principles of integrated care..$^{53}$

Although the added value of our model has to be empirically determined, we believe that it has a strong basis. During the development of our integrated disease management pathway, we used a robust and scientifically based method, that is, the seven-phase model of the EPA. ${ }^{23}$ With this method, several other care pathways have been successfully developed and implemented, including a pathway for acutely ill patients with COPD who were in need of hospitalization. ${ }^{54-57}$ In the seven-phase model, co-creation in the designing process is acknowledged to be crucial in establishing a supported innovative care model..$^{58}$ Therefore, early on in the designing process, we consulted different stakeholders, both with respect to their opinions regarding the care process and their views on the content of the integrated disease management pathway.

Notably, the content of our model addresses diseasespecific aspects based on knowledge regarding its complexity and heterogeneity, ${ }^{1}$ but it also includes features relating to the more general needs of patients with a chronic condition. We found inspiration for the latter in the CCM. ${ }^{24}$ The assumption of the CCM is that better outcomes of care in patients with chronic conditions, such as COPD, are to be expected as a result of the productive interaction between proactive health care professionals and an activated patient. To enable and support this productive interaction, several features of the health care system should be reconsidered and improved by united efforts. These improvements concern self-management strategies, decision support, delivery system design, and clinical information systems. ${ }^{26}$ In our COPDnet model, all these four elements are explicitly addressed. With the incorporation of the systematic measurement on outcomes (using PROMs) of the integrated care pathway, as a basis for the QMS, we supported the creation of a continuously learning organization. This will enable us to keep on introducing new improvements to our COPDnet model.

Despite our positive expectations with regard to the added value of our care pathway, we acknowledge some challenges in its use. Care according to the COPDnet model starts at the moment a patient with COPD is referred from primary care (GP) to secondary care (pulmonologist) because of persistent burden of disease. Hence, proper working of the COPDnet model presupposes timely and adequate medical diagnosis and a correct determination of the burden of disease by the GP. Under- or misdiagnosis of COPD and a wrong estimate of the burden of disease in primary care would result in absent, late, or improper referrals to secondary care and challenge the proper application of the COPDnet model. In addition, during the diagnostic workup of the pulmonologist, the medical diagnosis is verified and adjusted if indicated.

Our COPDnet model strongly relies on the reinforcement of self-management strategies and seeks to initiate behavioral change in patients. ${ }^{33,59}$ However, much is still unclear in this 
domain and requires further development. ${ }^{60}$ Also, our model requires a change in attitude on the part of the health care professionals. The one-dimensional medical perspective is abandoned to make way for a multidimensional biopsychosocial approach to patients, which is not an easy task for health care providers. ${ }^{61,62}$ Furthermore, our COPDnet model relies on an adequate interaction between health care professionals working in different settings within the health care system, which are primary, secondary, and tertiary care settings. This means that although communications can be easily digitally supported, in real life, communication appears to be not as easy as that. ${ }^{63-65}$

Finally, although our integrated disease management pathway has been established in a scientific manner and the content is in line with current insights, we acknowledge that the COPDnet model is complex. Significant investments may be needed to use the full model. These investments must focus on clear agreements on effective communications between health care professionals in order to facilitate the transfer of patients across the COPDnet model. In addition, education and training of health care professionals in the use of the different components will be required and are therefore integrated in the QMS. Further studies on the feasibility, health status benefits, and costs of the model will provide answers as to the added value of the COPDnet model.

\section{Conclusion}

A new integrated disease management pathway in patients with COPD, named COPDnet, has been designed according to current knowledge on important disease-specific aspects as well as on insights regarding effective care in patients with a chronic condition. The model provides the application of principles of a learning organization, through a continuous evaluation of the results. This in turn may lead to future adaptations of the model. Once the model is stable, it will be evaluated for its feasibility, health status benefits, and costs of care.

\section{Acknowledgments}

Heleen van der Niet, Jeanine Antons, and Jan Vercoulen are thanked for their valuable contributions during the designing process of the COPDnet integrated care model. Jeanine Antons is also thanked for her contributions during the revision of the manuscript, and Renata Straver is thanked for her linguistic support. This study was funded by unrestricted grants from AstraZeneca, Glaxo Smith Klein, Novartis, Chiesi, Takeda, Mundipharma, Teva, and Boehringer-Ingelheim.

\section{Disclosure}

The authors report no conflicts of interest in this work.

\section{References}

1. Agusti A, Calverley PM, Celli B, et al. Characterisation of COPD heterogeneity in the ECLIPSE cohort. Respir Res. 2010;11:122.

2. Wouters EF. Economic analysis of the Confronting COPD survey: an overview of results. Respir Med. 2003;97(suppl C):S3-S14.

3. Mannino DM, Buist AS. Global burden of COPD: risk factors, prevalence, and future trends. Lancet. 2007;370(9589):765-773.

4. Porter ME. What is value in health care? NEngl J Med. 2010;363(26): 2477-2481.

5. Porter ME, Larsson S, Lee TH. Standardizing patient outcomes measurement. $N$ Engl J Med. 2016;374(6):504-506.

6. Worth H, Buhl R, Criee CP, Kardos P, Mailander C, Vogelmeier C. The 'real-life' COPD patient in Germany: the DACCORD study. Respir Med. 2016;111:64-71.

7. Buhl R, Criee CP, Kardos P, et al. A year in the life of German patients with COPD: the DACCORD observational study. Int J Chron Obstruct Pulmon Dis. 2016;11:1639-1646.

8. Haughney J, Gruffydd-Jones K, Roberts J, Lee AJ, Hardwell A, McGarvey L. The distribution of COPD in UK general practice using the new GOLD classification. Eur Respir J. 2014;43(4):993-1002.

9. Ke X, Marvel J, Yu TC, et al. Impact of lung function on exacerbations, health care utilization, and costs among patients with COPD. Int JChron Obstruct Pulmon Dis. 2016;11:1689-1703.

10. Fuchs S, Henschke C, Blumel M, Busse R. Disease management programs for type 2 diabetes in Germany: a systematic literature review evaluating effectiveness. Dtsch Arztebl Int. 2014;111(26):453-463.

11. Lemmens KM, Nieboer AP, Huijsman R. A systematic review of integrated use of disease-management interventions in asthma and COPD. Respir Med. 2009;103(5):670-691.

12. Peytremann-Bridevaux I, Burnand B. Disease management: a proposal for a new definition. Int J Integr Care. 2009;9:e16.

13. Nici L, ZuWallack R; American Thoracic Society Subcommittee on Integrated Care of the CP. An official American Thoracic Society workshop report: the Integrated Care of The COPD Patient. Proc Am Thorac Soc. 2012;9(1):9-18.

14. Kruis AL, Smidt N, Assendelft WJ, et al. Integrated disease management interventions for patients with chronic obstructive pulmonary disease. Cochrane Database Syst Rev. 2013;10:CD009437.

15. Mendes de Oliveira JC, Studart Leitão Filho FS, Malosa Sampaio LM, et al. Outpatient vs. home-based pulmonary rehabilitation in COPD: a randomized controlled trial. Multidiscip Respir Med. 2010;5(6): 401-408.

16. Rea H, McAuley S, Stewart A, Lamont C, Roseman P, Didsbury P. A chronic disease management programme can reduce days in hospital for patients with chronic obstructive pulmonary disease. Intern Med $J$. 2004;34(11):608-614.

17. Smith BJ, Appleton SL, Bennett PW, et al. The effect of a respiratory home nurse intervention in patients with chronic obstructive pulmonary disease (COPD). Aust N Z J Med. 1999;29(5):718-725.

18. Sridhar M, Taylor R, Dawson S, Roberts NJ, Partridge MR. A nurse led intermediate care package in patients who have been hospitalised with an acute exacerbation of chronic obstructive pulmonary disease. Thorax. 2008;63(3):194-200.

19. Strijbos JH, Postma DS, van Altena R, Gimeno F, Koeter GH. A comparison between an outpatient hospital-based pulmonary rehabilitation program and a home-care pulmonary rehabilitation program in patients with COPD. A follow-up of 18 months. Chest. 1996;109(2): 366-372.

20. Achelrod D, Welte T, Schreyogg J, Stargardt T. Costs and outcomes of the German disease management programme (DMP) for chronic obstructive pulmonary disease (COPD)-A large population-based cohort study. Health Policy. 2016;120(9):1029-1039. 
21. Kayyali R, Odeh B, Frerichs I, et al. COPD care delivery pathways in five European Union countries: mapping and health care professionals' perceptions. Int J Chron Obstruct Pulmon Dis. 2016;11:2831-2838.

22. Long Alliantie Nederland (LAN) [Lung Alliance Netherlands]. Zorgstandaard COPD [Care Standard COPD]; 2016. Available from: http:// www.longalliantie.nl/zorgstandaard-copd. Accessed March 16, 2018. Dutch.

23. Vanhaecht K, Van Gerven E, Deneckere S, et al. 7-fasenmodel voor de ontwikkeling, implementatie, evaluatie en continue opvolging van zorgpaden [The 7 phase model to develop, implement, evaluate and continuously follow up care pathways]. Tijdschr Geneeskd. 2011;10:8. Dutch.

24. Wagner EH, Austin BT, Von Korff M. Improving outcomes in chronic illness. Manag Care Q. 1996;4(2):12-25.

25. Coleman K, Austin BT, Brach C, Wagner EH. Evidence on the Chronic Care Model in the new millennium. Health Aff. 2009;28(1):75-85.

26. Adams SG, Smith PK, Allan PF, Anzueto A, Pugh JA, Cornell JE. Systematic review of the chronic care model in chronic obstructive pulmonary disease prevention and management. Arch Intern Med. 2007;167(6): $551-561$.

27. Wagner EH, Austin BT, Davis C, Hindmarsh M, Schaefer J, Bonomi A. Improving chronic illness care: translating evidence into action. Health Aff. 2001;20(6):64-78.

28. Agusti A, MacNee W. The COPD control panel: towards personalised medicine in COPD. Thorax. 2013;68(7):687-690.

29. van den Akker EF, Van't Hul AJ, Birnie E, Chavannes NH, Rutten-van Molken MP, In't Veen JC. Comprehensive diagnostic assessment of health status of patients with asthma or COPD: a Delphi Panel Study among Dutch Experts. COPD. 2017;14(2):190-199.

30. Hillas G, Perlikos F, Tsiligianni I, Tzanakis N. Managing comorbidities in COPD. Int J Chron Obstruct Pulmon Dis. 2015;10:95-109.

31. van den Akker EF, van't Hul AJ, Chavannes NH, et al. Development of an integral assessment approach of health status in patients with obstructive airway diseases: the CORONA study. Int J Chron Obstruct Pulmon Dis. 2015;10:2413-2422.

32. Effing TW, Bourbeau J, Vercoulen J, et al. Self-management programmes for COPD: moving forward. Chron Respir Dis. 2012;9(1):27-35.

33. Effing TW, Vercoulen JH, Bourbeau J, et al. Definition of a COPD self-management intervention: International Expert Group consensus. Eur Respir J. 2016;48(1):46-54.

34. Hibbard JH, Mahoney ER, Stockard J, Tusler M. Development and testing of a short form of the patient activation measure. Health Serv Res. 2005;40(6 pt 1):1918-1930.

35. Hibbard JH, Stockard J, Mahoney ER, Tusler M. Development of the Patient Activation Measure (PAM): conceptualizing and measuring activation in patients and consumers. Health Serv Res. 2004;39(4 pt 1): 1005-1026.

36. Prochaska JO, DiClemente CC. Stages of change in the modification of problem behaviors. Prog Behav Modif. 1992;28:183-218.

37. Elwyn G, Dehlendorf C, Epstein RM, Marrin K, White J, Frosch DL. Shared decision making and motivational interviewing: achieving patient-centered care across the spectrum of health care problems. Ann Fam Med. 2014;12(3):270-275.

38. Michie S, van Stralen MM, West R. The behaviour change wheel: a new method for characterising and designing behaviour change interventions. Implement Sci. 2011;6:42.

39. Elwyn G, Frosch D, Thomson R, et al. Shared decision making: a model for clinical practice. J Gen Intern Med. 2012;27(10):1361-1367.

40. Spruit MA, Singh SJ, Garvey C, et al. An official American Thoracic Society/ European Respiratory Society statement: key concepts and advances in pulmonary rehabilitation. Am J Respir Crit Care Med. 2013;188(8):e13-e64.

41. Wilson IB, Cleary PD. Linking clinical variables with health-related quality of life. A conceptual model of patient outcomes. JAMA. 1995; 273(1):59-65.

42. van Ranst D, Otten H, Meijer JW, van't Hul AJ. Outcome of pulmonary rehabilitation in COPD patients with severely impaired health status. Int J Chron Obstruct Pulmon Dis. 2011;6:647-657.
43. Peters JB, Daudey L, Heijdra YF, Molema J, Dekhuijzen PN, Vercoulen JH. Development of a battery of instruments for detailed measurement of health status in patients with COPD in routine care: the Nijmegen Clinical Screening Instrument. Qual Life Res. 2009;18(7): 901-912.

44. Vercoulen JH. A simple method to enable patient-tailored treatment and to motivate the patient to change behaviour. Chron Respir Dis. 2012;9(4):259-268.

45. van der Molen T, Willemse BW, Schokker S, ten Hacken NH, Postma DS, Juniper EF. Development, validity and responsiveness of the Clinical COPD Questionnaire. Health Qual Life Outcomes. 2003;1:13.

46. Kruis AL, Soljak M, Chavannes NH, Elkin SL. COPD multidisciplinary team meetings in the United Kingdom: health care professionals' perceptions of aims and structure. COPD. 2016;13(5):639-641.

47. Ivers N, Jamtvedt G, Flottorp S, et al. Audit and feedback: effects on professional practice and healthcare outcomes. Cochrane Database Syst Rev. 2012;(6):CD000259.

48. Reticker AL, Nici L, ZuWallack R. Pulmonary rehabilitation and palliative care in COPD: two sides of the same coin? Chron Respir Dis. 2012;9(2):107-116.

49. Trappenburg JC, Monninkhof EM, Bourbeau J, et al. Effect of an action plan with ongoing support by a case manager on exacerbation-related outcome in patients with COPD: a multicentre randomised controlled trial. Thorax. 2011;66(11):977-984.

50. Kruis AL, Smidt N, Assendelft WJ, et al. Cochrane corner: is integrated disease management for patients with COPD effective? Thorax. 2014;69(11):1053-1055.

51. Kardos P, Vogelmeier C, Buhl R, Criee CP, Worth H. The prospective non-interventional DACCORD study in the National COPD Registry in Germany: design and methods. BMC Pulm Med. 2015;15:2.

52. Bourbeau J, Tan WC, Benedetti A, et al. Canadian Cohort Obstructive Lung Disease (CanCOLD): fulfilling the need for longitudinal observational studies in COPD. COPD. 2014;11(2):125-132.

53. Tottenborg SS, Thomsen RW, Nielsen H, Johnsen SP, Frausing Hansen E, Lange P. Improving quality of care among COPD outpatients in Denmark 2008-2011. Clin Respir J. 2013;7(4):319-327.

54. Panella M, Marchisio S, Brambilla R, Vanhaecht K, Di Stanislao F. A cluster randomized trial to assess the effect of clinical pathways for patients with stroke: results of the clinical pathways for effective and appropriate care study. BMC Med. 2012;10:71.

55. Panella M, Marchisio S, Demarchi ML, Manzoli L, Di Stanislao F. Reduced in-hospital mortality for heart failure with clinical pathways: the results of a cluster randomised controlled trial. Qual Saf Health Care. 2009;18(5):369-373.

56. Vanhaecht K, Sermeus W, Peers J, et al. The impact of care pathways for patients with proximal femur fracture: rationale and design of a cluster-randomized controlled trial. BMC Health Serv Res. 2012;12: 124.

57. Vanhaecht K, Sermeus W, Peers J, et al. The impact of care pathways for exacerbation of Chronic Obstructive Pulmonary Disease: rationale and design of a cluster randomized controlled trial. Trials. 2010; 11:111.

58. Grol R, Grol R. Improving Patient Care: The Implementation of Change in Health Care. 2nd ed. Chichester, UK; Hoboken, NJ, USA: Wiley Blackwell, BMJ/Books; 2013.

59. Jonkman NH, Schuurmans MJ, Jaarsma T, Shortridge-Baggett LM, Hoes AW, Trappenburg JC. Self-management interventions: proposal and validation of a new operational definition. J Clin Epidemiol. 2016; 80:34-42.

60. Kaptein AA, Fischer MJ, Scharloo M. Self-management in patients with COPD: theoretical context, content, outcomes, and integration into clinical care. Int J Chron Obstruct Pulmon Dis. 2014;9:907-917.

61. Young HM, Apps LD, Harrison SL, Johnson-Warrington VL, Hudson N, Singh SJ. Important, misunderstood, and challenging: a qualitative study of nurses' and allied health professionals' perceptions of implementing self-management for patients with COPD. Int J Chron Obstruct Pulmon Dis. 2015;10:1043-1052. 
62. Grol R, Grimshaw J. From best evidence to best practice: effective implementation of change in patients' care. Lancet. 2003;362(9391): 1225-1230.

63. Sampson R, Barbour R, Wilson P. Email communication at the medical primary-secondary care interface: a qualitative exploration. $\mathrm{Br} \mathrm{J}$ Gen Pract. 2016;66(648):e467-e473.
64. Sampson R, Barbour R, Wilson P. The relationship between GPs and hospital consultants and the implications for patient care: a qualitative study. BMC Fam Pract. 2016;17:45.

65. Sheu L, Fung K, Mourad M, Ranji S, Wu E. We need to talk: primary care provider communication at discharge in the era of a shared electronic medical record. J Hosp Med. 2015;10(5):307-310.

International Journal of COPD

\section{Publish your work in this journal}

The International Journal of COPD is an international, peer-reviewed journal of therapeutics and pharmacology focusing on concise rapid reporting of clinical studies and reviews in COPD. Special focus is given to the pathophysiological processes underlying the disease, intervention programs, patient focused education, and self management protocols.

\section{Dovepress}

This journal is indexed on PubMed Central, MedLine and CAS. The manuscript management system is completely online and includes a very quick and fair peer-review system, which is all easy to use. Visit $\mathrm{http}: / / \mathrm{www}$.dovepress.com/testimonials.php to read real quotes from published authors.

Submit your manuscript here: http://www.dovepress.com/international-journal-of-chronic-obstructive-pulmonary-disease-journal 